\title{
Thermo-Chemical Ablation During Reentrant and High Altitude Skipping Flight
}

\author{
M. Havstad, P. Carter
}

This article was submitted to $39^{\text {th }}$ American Institute of Aeronautics and Astronautics Aerospace Sciences Meeting, Reno, NV, January 8-11, 2001

\section{March 28, 2000}

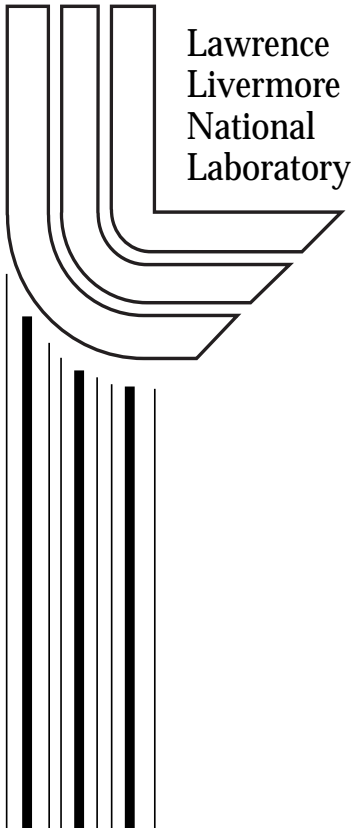




\section{DISCLAIMER}

This document was prepared as an account of work sponsored by an agency of the United States Government. Neither the United States Government nor the University of California nor any of their employees, makes any warranty, express or implied, or assumes any legal liability or responsibility for the accuracy, completeness, or usefulness of any information, apparatus, product, or process disclosed, or represents that its use would not infringe privately owned rights. Reference herein to any specific commercial product, process, or service by trade name, trademark, manufacturer, or otherwise, does not necessarily constitute or imply its endorsement, recommendation, or favoring by the United States Government or the University of California. The views and opinions of authors expressed herein do not necessarily state or reflect those of the United States Government or the University of California, and shall not be used for advertising or product endorsement purposes.

This is a preprint of a paper intended for publication in a journal or proceedings. Since changes may be made before publication, this preprint is made available with the understanding that it will not be cited or reproduced without the permission of the author.

This report has been reproduced directly from the best available copy.

Available to DOE and DOE contractors from the

Office of Scientific and Technical Information

P.O. Box 62, Oak Ridge, TN 37831

Prices available from (423) 576-8401

http:/ / apollo.osti.gov/bridge/

Available to the public from the National Technical Information Service

U.S. Department of Commerce 5285 Port Royal Rd., Springfield, VA 22161 http://www.ntis.gov/

OR

Lawrence Livermore National Laboratory Technical Information Department's Digital Library http://www.llnl.gov/tid/Library.html 


\title{
THERMO-CHEMICAL ABLATION DURING REENTRANT AND HIGH ALTITUDE SKIPPING FLIGHT
}

\author{
Mark Havstad and Preston Carter \\ The University of California \\ Lawrence Livermore National Laboratory \\ P.O. Box 808, L-140 \\ Livermore, CA 94551
}

\begin{abstract}
Thermo-chemical ablation during reentrant and high altitude skipping flights is treated using a variety of techniques. The solid material response is computed using heat-balance integrals, finite differences, and finite elements. The surface mass loss is computed using curve fits to the standard transport coefficient approach and by a surface kinetic model. Agreement between the approaches, when using the curve fits, is good. All approaches concur that for the skipping trajectory studied there is very little mass loss and surface temperatures remain in a range where the thermal protection system can be reused.
\end{abstract}

\section{INTRODUCTION}

The transient heating and chemical evolution of the surface and interior of both carbon and silicon based materials experiencing atmospheric reentry remain subjects of vigorous inquiry ${ }^{1,2,3,4,5,6,7,8}$. Among these, material response calculations have been done using the heat-balance integral ${ }^{1,2}(\mathrm{HBI})$, finite element ${ }^{3}(\mathrm{FE})$ and finite volume ${ }^{4}(\mathrm{FV})$ techniques. Coupled flow field calculations using viscous shock-layer ${ }^{5}$ and full NavierStokes ${ }^{6,7,8}$ techniques are not uncommon. Aspects of the operative surface thermochemistry are summarized in a fairly recent review ${ }^{9}$. Some of the more recent work has focused on surface kinetics ${ }^{10,11,12}$. However, integrating detailed kinetic models with both material response and flow field calculations is a challenge.

There are four objectives to this article. First, to show results for the surface temperature and heat flux to the carbon-carbon leading edge of Hypersoar, a proposed space vehicle characterized by a skipping trajectory in the upper atmosphere at altitudes between 35 to $60 \mathrm{~km}$. Second, to give a general formulation for the interaction of surface species and gaseous species which is integrated into a finite element conduction code (e.g., TOPAZ3D ${ }^{13}$ ) for material response. Third, to compare "standard" ablation calculations (curve fits to the $\mathrm{ACE}^{14}$ program) to a surface kinetic model. Fourth, to examine the surface kinetic formulation for stability and credibility.

To these ends the work begins with a brief review of surface mass and energy balances for an ablating material. A general formulation of the surface kinetic approach of Zhluktov and $\mathrm{Abe}^{12}$ is then given. These constructs are then utilized within HBI calculations of a 30 second reentrant flight of a carbon-carbon aeroshell. Rate of mass loss, temperature and heat flux at the stagnation point are shown for both the surface kinetic and the more standard approaches. Finite element and finite difference computations are then contrasted as well. Estimates of a leading edge temperature history during the high altitude (35 to $60 \mathrm{~km}$ ) skipping trajectory of Hypersoar are then given. Finally, results from the kinetic approach for several assumed gaseous concentration distributions are contrasted.

\section{Conservation Relations}

The mass and energy flows into and out of a volume of infinitesimal thickness centered on an ablating surface are shown in Figure 1. The mass balance equation is:

$$
\dot{m}_{a b}+\dot{m}_{e r}+\dot{m}_{\text {pyrgas }}=\dot{m}_{\text {und }}+\dot{m}_{\text {pyrgas }}
$$

Leaving the control volume on the fluid side are ablative, erosive and pyrolysis gas terms. Entering the control volume from the opposite side are the pyrolysis gas and the solid material (which enters because the control volume must be receding into the solid (underside) to stay centered on the ablating surface). Only carbon-carbon or graphite aeroshells are considered here (so pyrolysis terms drop out) and erosion is ignored for simplicity.

\footnotetext{
$¥$ Work performed under the auspices of the U.S. Department of Energy by Lawrence Livermore National Laboratory under Contract W-7405-Eng-48. "Copyright (C) 2001 by the American Institute of Aeronautics and Astronautics, Inc. All rights reserved."
} 
Figure 1. Surface mass and energy balances for ablator.
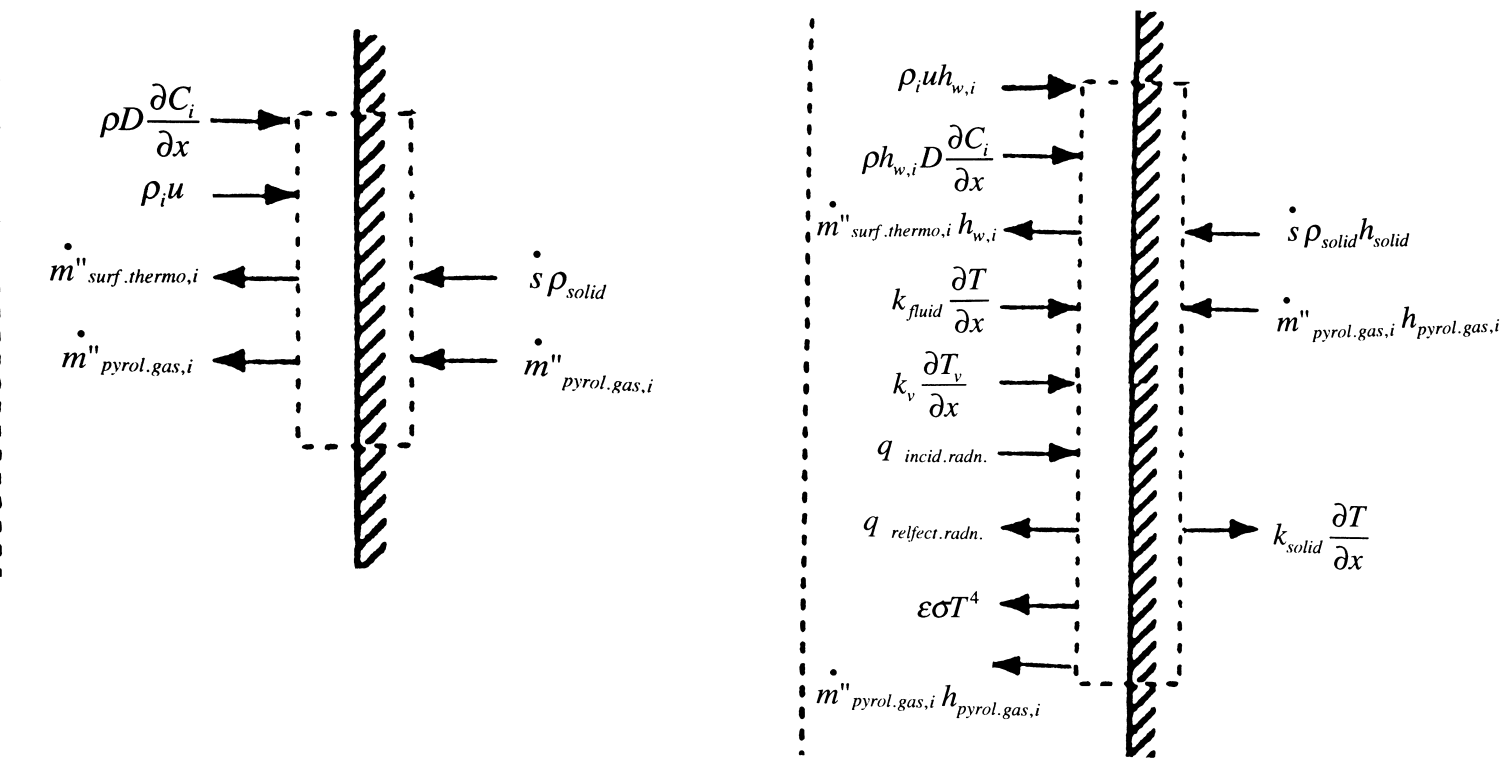

The energy balance equation for the same volume of infinitesimal thickness can be written:

$$
\dot{q}_{\text {ffcondn }}+\dot{q}_{\text {diff }}+\dot{q}_{\text {incradn }}=\dot{q}_{\text {solcondn }}+\dot{q}_{\text {reffradn }}+\dot{q}_{\text {emitrradn }}+\dot{q}_{\text {abspec }}
$$

Terms on the left indicate heat input to the control volume from the fluid side. The first two terms, the heat diffusion and mass diffusion contributions, are generally supplied by a computational fluid dynamics solution (CFD). The third term on the left is the incident radiation from the fluid side. On the right hand side are terms for the conducted heat into the interior of the solid, reflected and then emitted radiation and last the enthalpy carried out of the control volume by ablation products. In this work, the solid conductive terms will be treated with heat balance integrals (HBI), finite differences (FD) and then finite element (FE) formulations.

Historically, in the absence of a "full" CFD solution (conforming to the true wall boundary conditions), the transport to the wall from the fluid has been written in terms of a cold wall heat flux, $\mathrm{q}_{\mathrm{cw}}$. This is a heat flux that would occur if the wall stayed at some low initial ambient temperature and no ablative or pyrolysis products were generated (no blowing):

$$
\begin{aligned}
& \dot{q}_{f l c o n d n}+\dot{q}_{\text {diff }} \cong \dot{q}_{c w}\left(1-h_{w} / h_{\text {rec }}\right) \Phi_{\text {blow }} \Phi_{\text {HAL }} \\
& \dot{q}_{c w}=f\left(\rho_{e}, u_{e}, \text { shape }, \ldots\right)
\end{aligned}
$$

The recovery enthalpy, we take as the stagnation enthalpy of the fluid far from the surface. The wall enthalpy is the total enthalpy of the mixture of fluid

species at the temperature of the wall. The correction for erosion, $\Phi_{\mathrm{HAL}}$ is set to one for this work, though data are available in the open literature (Hove and Shih ${ }^{15}$ ). The correction for blowing, $\Phi_{\text {blow }}$, is derived from boundary layer film theory ${ }^{16}$ :

$\Phi_{\text {blow }}=a B_{o}^{\prime} /\left[\exp \left(a B_{o}^{\prime}\right)-1\right]$

A range of values for $a$ ( 0.3 to 1.3 ) have been used $^{9}$. The dimensionless surface mass flux $B_{o}^{\prime}$, is related to the Stanton number for mass transfer, $\mathrm{C}_{\mathrm{m}}$ :

$B_{o}^{\prime}=\dot{m}_{w} / \rho_{e} u_{e} C_{m}$

Although some ablative species may react with dissociated components of air to make radiatively participating constituents it is not uncommon to simplify radiation to a single term:

$\dot{q}_{\text {emittradn }}+\dot{q}_{\text {reflradn }}-\dot{q}_{\text {incradn }}=\varepsilon \sigma\left(T_{w}^{4}-T_{\text {ref }}^{4}\right)(6)$

Combining the above relations and writing the ablative transport term as a product of an ablative mass rate and an enthalpy difference we then get the relation for the heat flux into the surface:

$$
\begin{aligned}
& \dot{q}_{\text {solcondn }}=\dot{q}_{c w}\left(1-h_{w} / h_{\text {rec }}\right) \Phi_{\text {blow }} \Phi_{H A L} \\
& -\varepsilon \sigma\left(T_{w}^{4}-T_{r e f}^{4}\right)-\dot{m}_{a b}\left(h_{w}-h_{\text {und }}\right)
\end{aligned}
$$

Positive terms on the right hand side of Eq. 7 contribute to heat flow into the solid. The enthalpy of the solid material moving into the control volume from 
the "underside," (i.e. the solid side) is $h_{\text {und }}$. Eq. 7 gives the flux which is specified as a boundary condition into the solid.

The underside enthalpy was given by Potts ${ }^{1}$ :

$$
\begin{aligned}
& h_{\text {und }}=\int_{T_{\text {ref }}}^{T_{w}} c_{p} d T \\
& =C_{\infty}\left(\sqrt{T_{w}^{2}+D^{2}}-\sqrt{T_{r e f}^{2}+D^{2}}\right)
\end{aligned}
$$

The wall enthalpy is computed as described in Keenan and $\mathrm{Candler}^{33}$ with the vibrational temperature set to the wall temperature.

The magnitude of the ablative mass flux is estimated in two ways. First, a set of pressure and temperature dependent correlations to $\mathrm{ACE}^{14}$ computer calculations (developed by Potts ${ }^{1}$ ) are used. The correlations hold for the ablation of carbon-carbon in air and carbon-phenolic in air provided that the pyrolyzed species are inert. In general, pyrolysis gasses do react and shift the correlation curves. Second, a set of surface kinetic constraints are derived and used instead of the ACE fits.

Following Scala ${ }^{17}$, Potts ${ }^{1}$ used a blending of rate dependent ablation and equilibrium ablation:

$$
\frac{1}{\dot{m}_{a b}^{2}}=\frac{1}{\dot{m}_{R}^{2}}+\frac{1}{\dot{m}_{e q}^{2}}
$$

The rate dependent ablation is given in a variety of sources including Metzger et al. ${ }^{18}$ :

$$
\dot{m}_{R}=a_{R}\left(X_{O_{2}} P^{*}\right)^{0.5} \exp \left[-E_{R} / R_{\text {univ }} T\right]
$$

Values for the mole fraction of oxygen in air, $X_{O_{2}}$, the rate constant $a_{R}$ and the activation energy, $E_{R}$, are given in Potts ${ }^{1}$, where ACE was used to perform many equilibrium surface thermochemistry (EST) calculations. The nondimensional mass transfer rate was then fit to the wall temperature with nondimensionalized pressure, $P^{*}$, as a parameter. Using the unity Lewis number assumption, the curve fits for nondimensional mass transfer and the relations above for the blowing influenced heat transfer one obtains the ablative mass flux. Alternatively, one can compute the mass transfer based on a computed rate of surface reaction and sublimation at the wall given the species present and the wall temperature.

\section{Surface Kinetic Modeling}

A generalized version of the surface chemistry formulation given in Zhluktov and $\mathrm{Abe}^{12}$ begins with the expression for a single chemical reaction:

$a A+b B+\ldots \Leftrightarrow p P+q Q+\ldots$

A compact form of this expression is often written:

$$
\sum_{B} v_{B} B=0
$$

The accepted convention for this form is that the stoichiometric numbers, $v_{B}$, for the products are positive and the reactants are negative. Because surface species do not deplete as a surface reaction progresses (until the full thickness of the substrate is consumed), it is preferable to ignore the sign convention for products and reactants in the following formulation so that here a less compact form is used:

$$
\sum_{B} v_{B} B-\sum_{B} \mu_{B} B=0
$$

In this form the stoichiometric numbers are all positive and any of the species may appear on both sides of the reaction if desired. The $\nu_{\mathrm{B}}$ and $\mu_{\mathrm{B}}$, are stoichiometric numbers for reactants and products respectively. For a set of $\mathrm{Q}$ elementary reactions we can write a generalization of the above relation:

$$
\sum_{w=1}^{W} v_{q w} B_{w}-\sum_{w=1}^{W} \mu_{q w} B_{w}=0
$$

The index $q$ runs from 1 to $\mathrm{Q}$. The index $w$ runs from 1 to $\mathrm{W}$, the number of gaseous species present.

For a set of Q surface reactions, a set of $L$ surface atoms are defined. For example, oxygen, carbon and nitrogen might attach themselves to a bare tungsten surface and then $L$ would be 4 and the surface atomic concentration of atom $l$ would be given by $\Theta_{1}$. The $\mathrm{O}$, $\mathrm{C}$, and $\mathrm{N}$ are referred to as adatoms since they are adsorbed by the tungsten sites of the substrate. For oxygen and nitrogen interacting with solid carbon $l$ would run from 1 to 3 . The gaseous species are not variables here, they are constants passed to the surface chemistry formulation from some other processor, for example a CFD solver. The surface atom fractions are the variables in a general equation for the $\mathrm{Q}$ surface reactions: 


$$
\begin{aligned}
& \sum_{w=1}^{W} v_{q w} B_{w}-\sum_{w=1}^{W} \mu_{q w} B_{w} \\
& +\sum_{l=1}^{L} \eta_{q l} \theta_{l}-\sum_{l=1}^{L} \lambda_{q l} \theta_{l}=0
\end{aligned}
$$

The reaction rates, $r_{q}$, for the $\mathrm{Q}$ reactions can be written from the above relation:

$$
\begin{aligned}
& r_{q}=k_{f q} \prod_{w=1}^{W}\left[P X_{q w}\right]^{v_{q w}} \prod_{l=1}^{L} \theta_{l}^{\eta_{q l}} \\
& -k_{r q} \prod_{w=1}^{W}\left[P X_{q w}\right]^{\mu_{q w}} \prod_{l=1}^{L} \theta_{l}^{\lambda_{q l}}
\end{aligned}
$$

At present, interactions between more than one gaseous species and an adatom in a single reaction are ignored. Thus all of the stoichiometric numbers for the gaseous species are zero or one. If this were not the case, the above relation would need revision. The forward and backward reaction rate constants, $k_{f q}$ and $k_{r q}$, are specified from a combination of theory and experiments. The definition of the equilibrium constant relates the forward and backward rates:

$$
K_{q}=\frac{k_{f q}}{k_{r q}}
$$

Values for particular equilibrium constants as a function of temperature are given in the $\mathrm{JANAF}^{19}$ tables or in other chemical references. The following form for the forward reaction rate encompasses a number of prevalent forms ${ }^{12}$.

$$
\begin{aligned}
& k_{f q}=\varepsilon_{q} f_{q} S_{q} e^{T_{a q} / T} \\
& S_{q}=1, \text { or } S_{q}=B k T / h \\
& f_{q}=P_{o} / \sqrt{2 \pi m_{i} k T}, \text { or } f_{q}=1
\end{aligned}
$$

The form of $f_{q}$ follows from the rate at which a gas at pressure $P_{o}$ bombards a solid surface, rate $=$ $P_{o} /(2 \pi m k T)^{1 / 2}$, though here $P_{o}$ is a reference pressure. The value of $m$ above is the mass of the appropriate atom or molecule. The constant $T_{a q}$ is the activation temperature for the onset of the reaction. The $S_{q}$ term allows for a surface site density, $B$, to affect the reaction rate. Zhluktov and $\mathrm{Abe}^{12}$ set several $\varepsilon_{q}$ to 1 but sometimes it is varied until a best fit to data is obtained. Backward reaction rate constants may also take this form.
In this formulation there are $L$ unknown surface concentrations and $4 Q$ more unknowns, $r_{q}, k_{r q}, k_{f q}$ and $K_{q}$. The definition of the equilibrium constant, the reaction rate equations and the relations for the reaction rate constants provide $3 Q$ relations. Equilibrium constant data provides $Q$ more relations. The $\mathrm{JANAF}^{19}$ tables are one choice for this data but simple relations are also available for some key materials. For example, carbon sublimation has been represented in these and other forms:

$$
\begin{aligned}
& K_{q}=c_{1}-c_{2} / T \\
& K_{q}=c_{1} T^{c_{2}} e^{-\frac{T_{a}}{T}}
\end{aligned}
$$

The first of the above two equations was used by Scala $^{17}$ with carbon sublimation and air species data. The second was used by Blottner ${ }^{20}$ with data for the coefficients credited to Zavitsanos ${ }^{21}$. Equilibrium constant expressions for mobile and immobile adsorption are also available ${ }^{12}$ :

$$
\begin{aligned}
& \frac{1}{K_{q}}=B \frac{k T}{P_{o}}\left(\frac{2 \pi m k T}{h^{2}}\right)^{1 / 2} e^{-\frac{T_{a}}{T}} \\
& \frac{1}{K_{q}}=\frac{k T}{P_{o}}\left(\frac{2 \pi m k T}{h^{2}}\right)^{3 / 2} e^{-\frac{T_{a}}{T}}
\end{aligned}
$$

Finally, the $K_{q}$ are not independent, since the gaseous mole fractions are interrelated. Thus we can also write:

$$
K_{q}=\prod_{w=1}^{W} K_{w}^{y_{q, w}} \prod_{l=1}^{L} K_{l}^{u_{q, l}}
$$

Here the $K_{w}$ represent gaseous data, usually from the $\mathrm{JANAF}^{19}$ tables, and the $K_{l}$ represent data supplied by any other defined format. The exponential powers, $y$ and $u$ above are determined by the gaseous and the surface chemistry models.

To close the problem $L$ more relations are required. Because the sum of all surface concentrations is unity the derivative of the sum must be zero:

$$
\sum_{l=1}^{L} \frac{\partial \theta_{l}}{\partial t}=0
$$

It will be common to treat systems where all but one of the surface atoms are adatoms so that the last surface atom defined is the bare substrate material. In this case it is convenient to rewrite the above relation: 


$$
\frac{\partial \theta_{L}}{\partial t}=-\sum_{l=1}^{L-1} \frac{\partial \theta_{l}}{\partial t}
$$

Finally $L-1$ additional relations can be written for the adatoms:

$$
\frac{\partial \theta_{l}}{\partial t}=\sum_{q=1}^{Q}-\eta_{q l} r_{q}+\lambda_{q l} r_{q}
$$

These relations express the fact that the rate at which the $l$-th adatom builds up on the surface is given by the rate that it forms in specific reactions in the set of $Q$ reactions less the rate at which it is desorbed in the $Q$ reactions. For the case of two or more types of "substrate" atom we would have two or more relations like the one above for the $L$-th atom and then the remaining L-2 relations would be divided into two subgroups. Each subgroup set of relations would express the fact that adatoms build up and desorb upon each type of substrate atom at forward and backward rates given by some subset of the $Q$ reactions. For each time step the system of kinetics equations is given the candidate wall temperature and an ordinary differential equation solver $\left(\mathrm{VODE}^{23}\right)$ is used to obtain the surface species concentrations and the reaction rates. Solution for the ablated mass rate depends on the reaction rates and stoichiometry. For example, sublimation of $\mathrm{C}$ and $\mathrm{C}_{3}$ might proceed at elevated temperatures during reentry along with release of $\mathrm{CO}$ by several mechanisms. The rates of these reactions and the masses of substrate material in each, 12, 36 and $12 \mathrm{~kg} / \mathrm{kg}$-mol, determines the rate of material lost. A specific chemical system for this formulation (again due to Zhluktov and $\mathrm{Abe}^{12}$ ) is:

1.) $O+(C) \Leftrightarrow(C-O)$

2.) $O_{2}+2(C) \Leftrightarrow 2(C-O)$

3.) $\mathrm{O}_{2}+(\mathrm{C}) \Leftrightarrow(\mathrm{C}-\mathrm{O})+\mathrm{O}$

4.) $\mathrm{CO}_{2}+(\mathrm{C}) \Leftrightarrow(\mathrm{C}-\mathrm{O})+\mathrm{CO}$

5.) $(C-O) \Leftrightarrow C O+(C)$

6.) $\mathrm{O}+(\mathrm{C}-\mathrm{O}) \Leftrightarrow \mathrm{CO}_{2}+(\mathrm{C})$

7.) $2(\mathrm{C}-\mathrm{O}) \Leftrightarrow \mathrm{CO}_{2}+2(\mathrm{C})$

8.) $(C) \Leftrightarrow C+(C)$

9.) $2(C) \Leftrightarrow C_{2}+2(C)$

10.) $3(C) \Leftrightarrow C_{3}+3(C)$

11.) $N+(C) \Leftrightarrow(C-N)$

12.) $(C-N)+N \Leftrightarrow N_{2}+(C)$

Items in parenthesis are solid species and due to the macroscopic thickness of the substrate do not deplete (hence several of the above relations do not "balance" on an elemental basis). Reactions 1 through 3, when they go forward, describe "putting $\mathrm{O}$ atoms on the surface" (adsorption). Reactions 5 to 7, when going forward, describe the release of a $\mathrm{CO}$ or $\mathrm{CO}_{2}$ molecule to the gas phase. Reaction 4 does both of the above, an $\mathrm{O}$ atom is put on the surface and a $\mathrm{CO}$ molecule is released. Reactions 8,9 and 10 describe sublimation of carbon (as $\mathrm{C}, \mathrm{C}_{2}$ and $\mathrm{C}_{3}$ species). Reactions 11 and 12 describe cyanogen formation and nitrogen desorption respectively. Both simpler and more complex sets of reactions can be specified but the above set is a practical choice given the slower rates of reaction thought to apply to all others. Zhluktov and $\mathrm{Abe}^{12}$ gave the reaction rates for the system:

$$
\begin{aligned}
& r_{1}=k_{f 1}\left(P X_{o} \theta^{o}-\theta_{o} / K_{1}\right) \\
& r_{2}=k_{r 2}\left[K_{2} P X_{o_{2}}\left(\theta^{o}\right)^{2}-\left(\theta_{o}\right)^{2}\right] \\
& r_{3}=k_{f 3}\left(P X_{o_{2}} \theta^{o}-P X_{o} \theta_{o} / K_{3}\right) \\
& r_{4}=k_{f 4}\left(P X_{c o_{2}} \theta^{o}-P X_{c o} \theta_{o} / K_{4}\right) \\
& r_{5}=k_{f 5}\left(\theta_{o}-P X_{c o} \theta^{o} / K_{5}\right) \\
& r_{6}=k_{f 6}\left(P X_{o} \theta_{o}-P X_{c o_{2}} \theta^{o} / K_{6}\right) \\
& r_{7}=k_{f 7}\left[\left(\theta_{o}\right)^{2}-P X_{c o_{2}}\left(\theta^{o}\right)^{2} / K_{7}\right] \\
& r_{8}=k_{r 8} \theta^{o}\left(K_{8}-P X_{c}\right) \\
& r_{9}=k_{r 9}\left(\theta^{o}\right)^{2}\left(K_{9}-P X_{c_{2}}\right) \\
& r_{10}=k_{r 10}\left(\theta^{o}\right)^{3}\left(K_{10}-P X_{c_{3}}\right) \\
& r_{11}=k_{f 11}\left(P X_{N} \theta^{o}-\theta_{N} / K_{11}\right) \\
& r_{12}=k_{r 12}\left(K_{12} P X_{N} \theta_{N}-P X_{N_{2}} \theta^{o}\right)
\end{aligned}
$$

The fraction of surface atom sites covered by oxygen is $\theta_{O}$, covered by nitrogen is $\theta_{N}$, and remaining bare carbon is $\theta^{\circ}$. Of course the reaction rates are functions of surface temperature and constants.

For the gaseous phase beside the ablator surface, the set of $W$ values of $X_{w}$, most calculations here have used $X_{N_{2}}=.68, X_{C O}=0.31, X_{O}=0.002$ and the remainder of the mole fractions zero. Until we link these material response calculations with a CFD solver we use this rough approximation to the mass fractions reported in Hassan and Kuntz ${ }^{3}$.

The forward and backward reaction rate constants and the interrelation of the equillibrium constants given by Zhluktov and $\mathrm{Abe}^{12}$ have been used here. 
The equilibrium constant for the sublimation of atomic carbon, $K_{8}$, can be obtained from a variety of sources. Four sources, each of which has been useful to ablative reentry formulations of the past 20 years, are Scala and Gilbert ${ }^{17}$ (1964), Blottner ${ }^{20}$ (1970), Baker ${ }^{24}$ (1977) and Palmer and Shelef ${ }^{25}$ (1968). Zhluktov and $\mathrm{Abe}^{12}$ have used the results of Blottner for $K_{8}$ in their work because it gives a higher ablation rate, but here Palmer and Shelef ${ }^{25}$ is most frequently used because it gives ablation in agreement with Scala ${ }^{17}$ and it seems to be in common use ${ }^{4}$.

The transient form of the constraint on site occupation is:

$-\frac{d \theta^{o}}{d t}=\frac{d \theta_{o}}{d t}+\frac{d \theta_{N}}{d t}$

Lastly, the first 7 reactions treat oxygen interaction with the surface and the final 2 reactions treat nitrogen interaction with the surface. Thus the rates of the first 7 reactions can be combined to describe how the oxygen population on the surface varies and the last 2 reactions can be combined to describe how the nitrogen population on the surface varies:

$$
\begin{aligned}
& \frac{d \theta_{o}}{d t}=r_{1}+2 r_{2}+r_{3}+r_{4}-r_{5}-r_{6}-2 r_{7} \\
& \frac{d \theta_{N}}{d t}=r_{11}-r_{12}
\end{aligned}
$$

In this system the substrate mass loss rate is:

$$
\dot{m}_{a b}=m_{c a r}\left(r_{5}+r_{6}+r_{7}+r_{8}+2 r_{9}+3 r_{10}\right)
$$

Only those reactions which involve removal of a substrate (carbon) atom contribute to mass loss and surface recession. However, once linked to a fluid calculation, the flux of each species from the wall into the boundary layer is required as the proper boundary condition for the flow calculation. These species production rates on the surface are readily computed from the solution for the twelve rates of reaction.

The ablated mass flux, whether computed by curve fits or equation 29 above, is coupled to the various conduction solutions by equation 7. For HBI, the treatment of conduction is well described in Potts ${ }^{1}$ and Leone et. al. ${ }^{2}$ For the finite difference and finite element methods, the heat flux is a nonlinear boundary condition. At each time step the conduction equation is repeatedly solved until the temperature dependent heat load converges. In the finite difference form, the ablated flux, surface recession and surface temperature are nodal quantities. In contrast, with the finite element form, the ablated flux is computed for three or four sided surface areas (faces of finite elements) defined as ablation segments on input. The nodal temperatures and surface shape functions are used to determine a segment wall temperature for the ablation mass flux calculation. The ablated heat flux is then distributed among the nodes using the segment shape functions.

\section{Results}

\section{A) Comparison of Computational} Approaches for a Carbon-Carbon Aaeroshell

Four different approaches to computing the thermal response of a reentering carbon-carbon aeroshell are compared here. The first approach is what might be called the standard HBI (Potts ${ }^{1}$ ). The second is the refined HBI approach given by Leone ${ }^{2}$. The Leone calculation shown here differs from that given in the citation in that the flight and material properties have been revised to match those of the Potts calculation. (The original Leone work had used a 40 second rather than a 30 second descent from altitude and had considered a carbon-phenolic aeroshell.) The third approach uses a finite difference calculation for the onedimensional conduction at the nose rather than the HBI (in effect zero-dimensional). We refer to this as the Thomas approach because the well-known Thomas algorithm is used to solve the conduction equation. All of these first three approaches use the curve fits to $\mathrm{ACE}^{14}$ noted above to treat the mass loss portion of the reentry heat and mass transfer. A new aspect of the work here is that these three calculations, and three more using the surface kinetics approach, are done for identical flight and material properties. The three surface kinetic calculations use the surface chemistry model formulated by Zhluktov and Abe ${ }^{12}$.

The Potts, Leone and Thomas approaches are compared in Figures 2 to 4 . The Potts calculations shown here agree very well with the results of the 1995 paper. It is reasonable to expect the Leone results to be the more accurate of the two (when compared to an idealized calculation or flight data) because the Leone approach 1) makes a more realistic attempt to treat the rise in temperature which should occur at the back face of the aeroshell and 2) uses a more flexible and higherorder temperature profile integrated through the thickness of the aeroshell. The closeness of the results for temperature (Fig. 2), heat flux (Fig. 3) and surface recession (Fig. 4) indicates that the HBI approach is being properly applied. 
Figure 2. Wall temperature versus time.

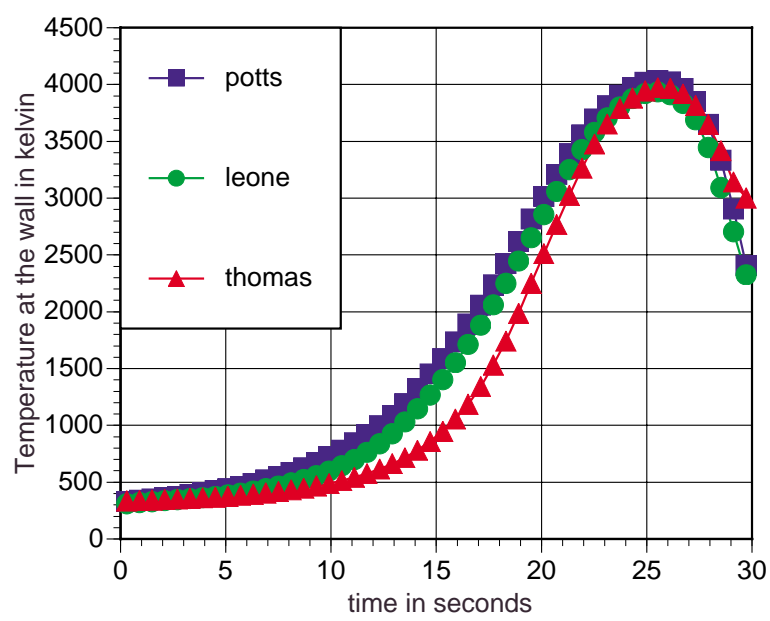

Figure 3. Comparison of computed heat fluxes.

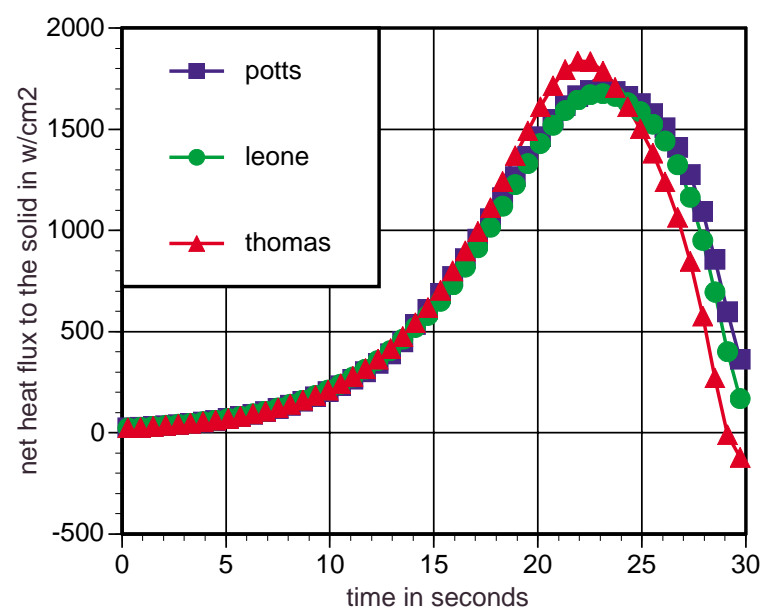

Figure 4. Surface recession versus time.

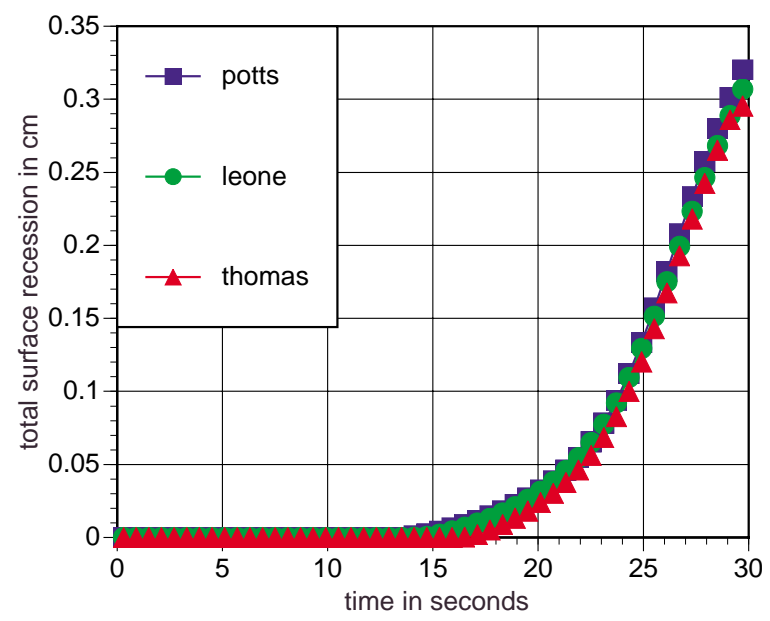

The discrepancies among these calculations are also illuminating. As with Potts' own comparison to finite difference calculations one finds that the HBI wall temperature is slightly quicker to respond in the early portion of the flight and thence the heat flux is slightly slower to respond. The results shown here also agree with Potts' comparison to finite differences in two more ways. As shown in Figure 4, the total ablated material (and thence the surface recession) over the history of the flight is nearly identical for the three methods. Also, the wall temperature drops off more sharply over the final 3 or 4 seconds of the flight for the two HBI techniques. Thus, the three approaches largely agree and the noted differences (between HBI and FD) are consistent with prior work.

Surface kinetic and ACE based ablative calculations are compared in Figure 5. The ordinate is the instantaneous ablative rate, i.e. the mass loss rate in grams $/ \mathrm{cm}^{2}$-sec. The three kinetic calculations shown are for differing gas mixtures flowing over the aeroshell. Each of the mixtures contains $68 \% \mathrm{~N}_{2}$ but varying amounts of $\mathrm{CO}$ and $\mathrm{O}$. The low mass rate case contains no $\mathrm{O}$ and $32 \% \mathrm{CO}$. The high mass rate case contains $0.5 \% \mathrm{O}$ and the middle mass rate case contains $0.25 \%$ O. Clearly, the quality of surface kinetic ablative calculations will be very strongly dependent on the flow field solution for gas composition at the wall (which is a strong function of both gas kinetic calculations and species diffusion relationships in the boundary layer). This implies that it will take interaction with a true flow solver to do the full troubleshooting and validation of the surface kinetic implementation of ablation within TOPAZ3D or any other solid material response code. It should be noted that the finite difference calculation as fielded above (and labeled ZHLUKTOV) is not a fully consistent or a fully ACE independent calculation. The mass flux computed from surface kinetics considerations used 1) the stagnation pressure determined by the trajectory altitude and velocity and 2) the wall temperature determined by the ACE based finite difference calculation. In theory, this link to ACE is unnecessary and could be replaced by a nonlinear iteration between the wall heat flux calculation and the surface kinetics. However, rather than face potential stability problems, this complexity was deferred to the finite element code implementation below.

For both the ACE and surface kinetics formulations fielded in TOPAZ3D, the computation of the ablated mass flux is done in a fully consistent non-linear iteration. From the latest temperatures computed at any given time step, the code solves for the surface species and mass flux using the chemical kinetics or other constraints provided. The mass flux is used within a surface energy balance to compute wall heat flux for each ablation segment. The heat loads are then used to compute a new vector of nodal temperatures. Only when both the loads and the temperatures converge does the code proceed to the next time step. 
Figure 5. Ablative mass flux versus time.

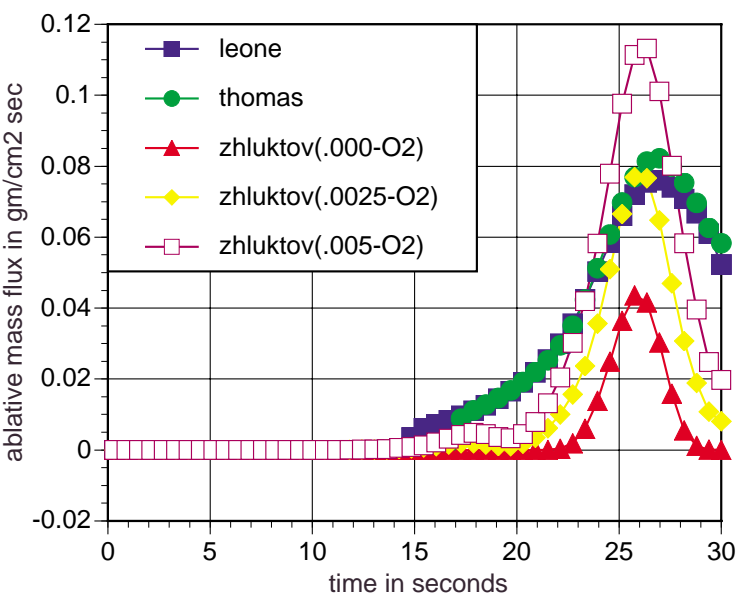

Although the surface kinetics option is computing the ablated mass flux without the use of results from ACE, there are at least two aspects of this work which should be kept in mind as future development proceeds. First, all calculations depend on a user-supplied vector of gaseous species mole fractions and property data. Once TOPAZ3D is linked to a CFD code this information will be provided by the latest CFD solution (or an interpolation between solutions) but for now the vector is a constant user input. Second, the code is still using a simple expression for the dependence of aerodynamic heating on free stream velocity and altitude (given in the Potts ${ }^{1}$ paper but originally due to Allen and Eggers $^{26}$ ). This aerodynamic heating will also be provided by a CFD code.

In order to check the finite element implementation, a special version of THOMAS was created which used temperature independent properties for the carbon-carbon aeroshell (to ensure that treatment of material properties did not differ between the FD and FE formulations). This version was then run for the 30 second descent. Figures 6 to 8 contrast the results from this version of THOMAS to TOPAZ3D ${ }^{13}$ calculations using the ACE based option. In Figure 6 we find that the aeroshell surface temperatures are nearly identical for most of the flight. The difference in peak temperature between the two calculations is $0.13 \%$. Figure 7 compares the computed heat fluxes to the aeroshell. Agreement is again good with the difference between peak fluxes $1.3 \%$. Figure 8 is important because it considers a quantity which ultimately could alter or even destabilize a coupled CFD solution: wall recession rates (in $\mathrm{cm} / \mathrm{sec}$ ). The recession rate is the ablative mass flux (in $\mathrm{gm} / \mathrm{cm}^{2}$-sec) divided by the constant aeroshell density $\left(1.9 \mathrm{gm} / \mathrm{cm}^{3}\right)$. Thus the figure confirms that the blown gasses, which are the thermal calculation feedback into a CFD computation (along with the aeroshell shape change which alters the boundary of the
CFD mesh), are being performed as desired in the TOPAZ3D calculation.

Figure 6. Wall temperatures computed by THOMAS and TOPAZ3D.

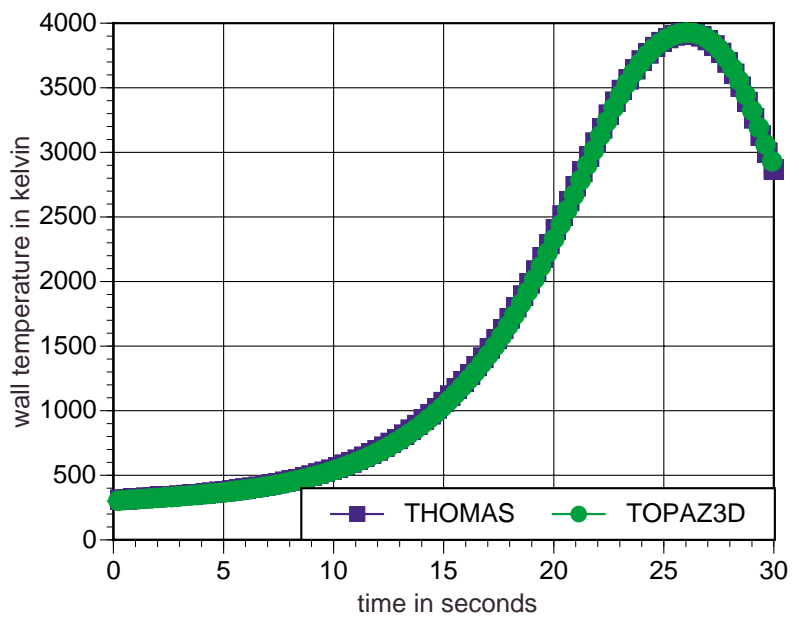

Figure 7. Heat fluxes computed by THOMAS and TOPAZ3D.

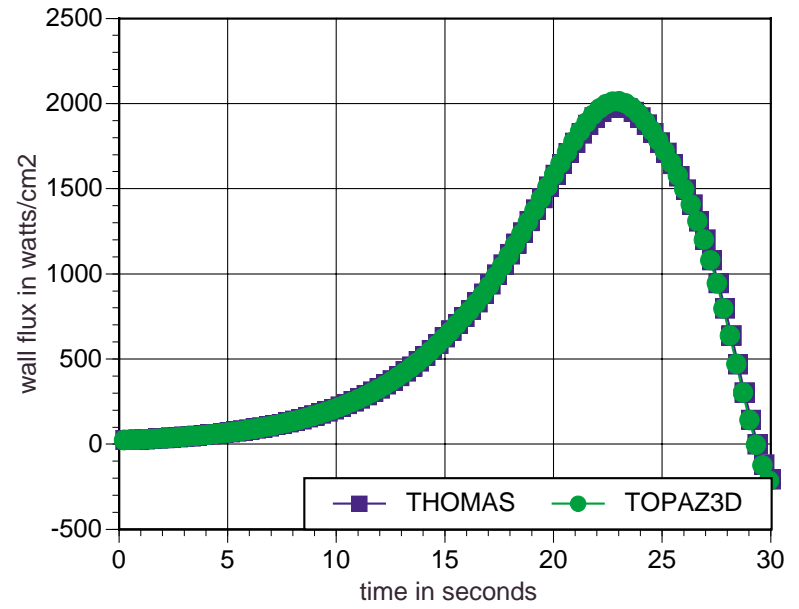


Figure 8. Surface recession rates computed by THOMAS and TOPAZ3D.

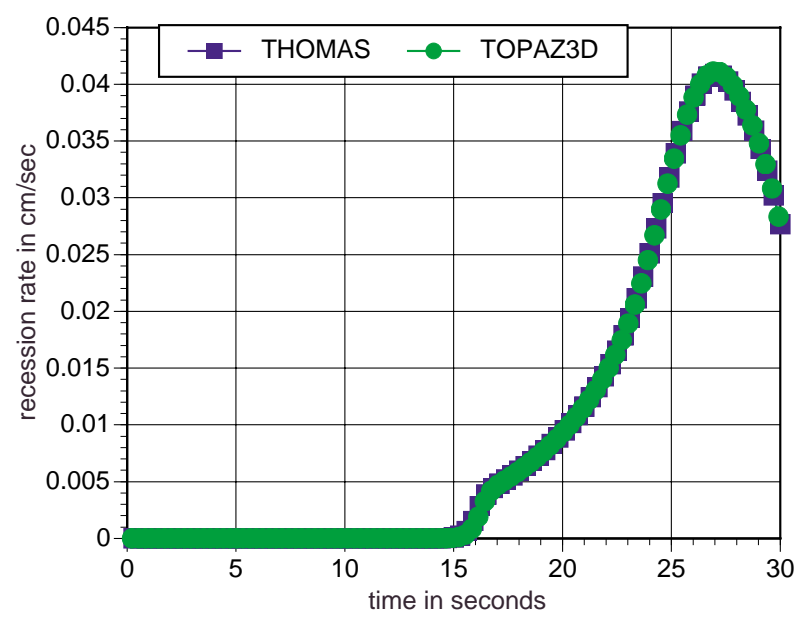

B) Comparison of ACE Based and Surface Kinetic Options within TOPAZ3D

The ACE based and surface kinetic options within TOPAZ3D can ostensibly be used to compute identical reentry cases. In fact, each approach has its shortcomings at present and it will take considerably more development before the kinetics approach can give verified results for all ablated species over an entire flight. Figures 9 to 11 compare temperatures, heat fluxes and surface recession for the two approaches applied to a simple one-dimensional geometry, a stack of elements 8 deep and 2 by 2 across (thus 4 ablative surface segments). Figure 9 shows that computed surface temperatures only differ in the vicinity of the peak (at about 26 seconds into the flight) because at other times the ablation is too small to significantly alter surface temperature with either approach. Figure 10 compares heat flux to the aeroshell. Agreement is again good, with the only noticeable difference being after about 24 seconds, where the surface recession rates (and therefore ablative mass fluxes) differ.

Figure 11 contrasts the computed surface recession rates. The ACE results are a combination of equilibrium and non-equilibrium relations collapsed to curve fits. In contrast, the surface kinetic approach fielded here uses the reaction kinetics selected to match carbon-carbon reacting at the low pressures present in the neighborhood of $70 \mathrm{~km}$ altitude, where thermal conditions were judged to be most severe for the Japanese planetary probe under consideration in that study. Some of the carbon reaction kinetics are pressure dependent and are therefore not presently well formulated for the lower altitude portions of the 30 second descent under study here. Thus the discrepancy between the ACE and kinetic approaches evident in Figure 11 should not be surprising. Choosing better sets of parameters for lower altitudes, or adding pressure dependent relations to the surface chemistry options list or simply adding an equilibrium based computational capability appropriate to the higher pressures present at low altitudes are three possible ways to further develop the surface chemistry option. The kinetics based recession rates are significantly lower at low temperatures and higher at high temperatures, i.e., the input parameters are inappropriate for the pressures operative at 25 seconds and later (i.e. below $15.5 \mathrm{~km}$ where atmospheric pressure can be idealized as $0.19 \mathrm{~kg} / \mathrm{m}^{3}$ compared to $1.6^{*} 10^{-4}$ at $75 \mathrm{~km}$

Figure 9. Temperatures computed by ACE curve fits and surface kinetic models.

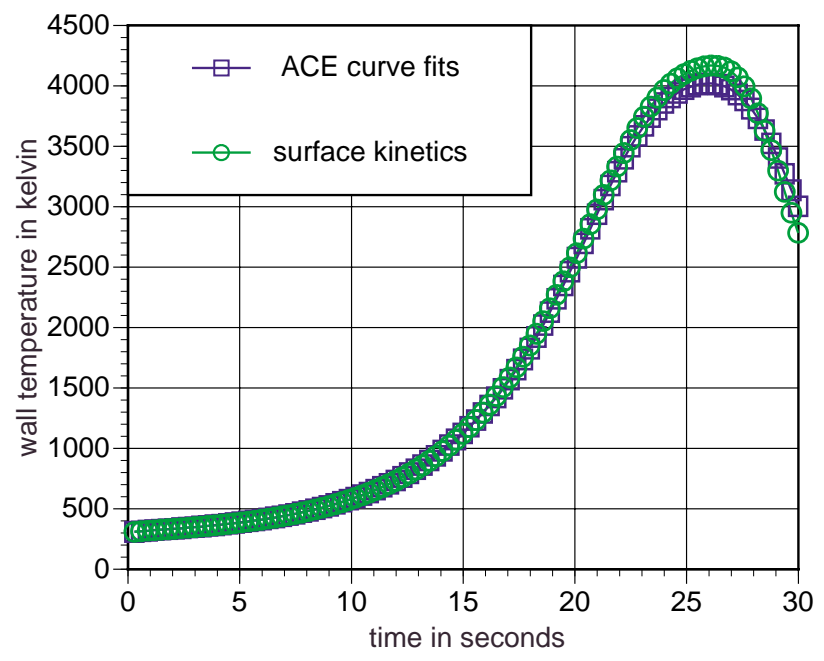

Figure 10. Wall heat fluxes computed by ACE curve fits and surface kinetic models.

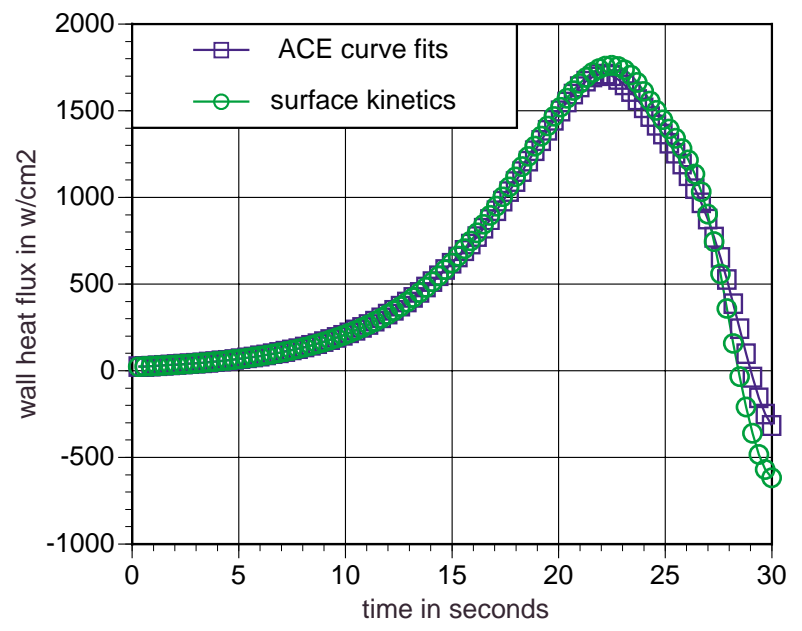


Figure 11. Surface recession rates computed by ACE curve fits and surface kinetic models.

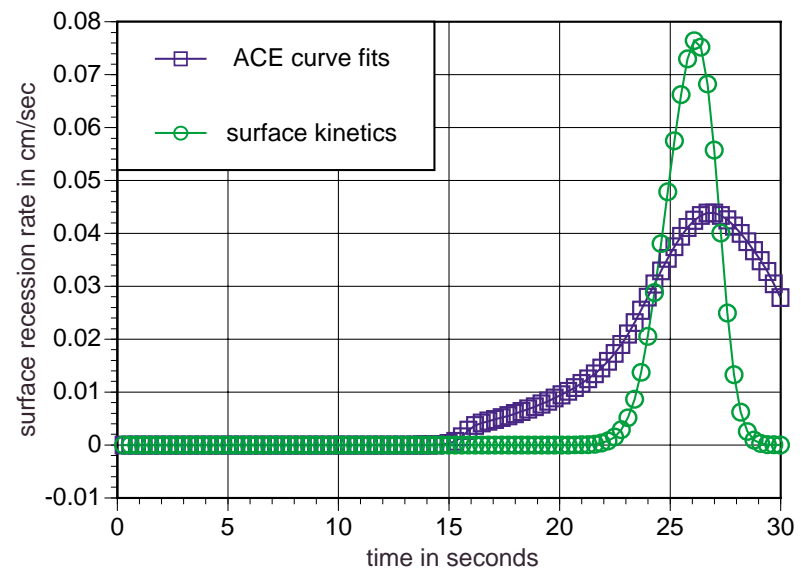

C) Estimates of Hypersoar Thermal

\section{Histories}

Hypersoar is a proposed vehicle for transcontinental travel with a "skipping" trajectory. The vehicle's engines fire for short periods when the trajectory drops into the 30 to $45 \mathrm{~km}$ altitude range and then the vehicle glides through an ascent and descent in the 45 to $60 \mathrm{~km}$ range. This sinusoidal trajectory is repeated after the boost phase of the flight and until the descent to surface phase. The trajectory is crudely represented here with a cosine function:

$$
\text { altitude }=G_{1}+G_{2} \cos \left(2 \pi t / G_{3}\right)
$$

Values for $\mathrm{G}_{1}$ (mean height), $\mathrm{G}_{2}$ (amplitude) and $\mathrm{G}_{3}$ (period) are typically $47.5 \mathrm{~km}, 12.5 \mathrm{~km}$ and 240 seconds respectively. For these trajectories a constant vehicle velocity of $3000 \mathrm{~m} / \mathrm{s}$ is used with a nose radius of $10 \mathrm{~cm}$. and a carbon-carbon thermal protection system thickness of $5 \mathrm{~cm}$. These are very approximate representations but adequate for the scoping calculations considered here. Figure 12 shows the temperature histories for 3 nodes of the TPS in a TOPAZ3D calculation for a 4800 second simulation of a Hypersoar flight. The 3 nodes are located on the surface (\#10), middle (\#14) and back face of the TPS (\#18). Using the surface kinetic option in TOPAZ3D the slightly cooler temperature profiles shown in Figure 13 are obtained. Since the kinetic model was formulated for application to the Japanese planetary probe at $70 \mathrm{~km}$, the thermal results shown ought to be reasonably accurate. Both calculations confirm that thermal effects at the leading edges of Hypersoar are not in the range for significant ablation and thus the TPS is reusable.
Figure 12. Hypersoar trajectory using TOPAZ3D with ACE curve fit option.
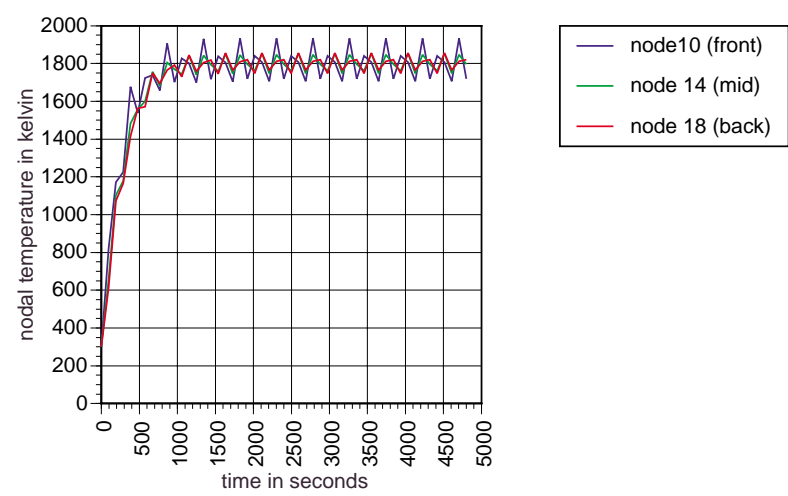

Figure 13. Nodal temperature histories for Hypersoar aeroshell using TOPAZ3D with surface kinetic option
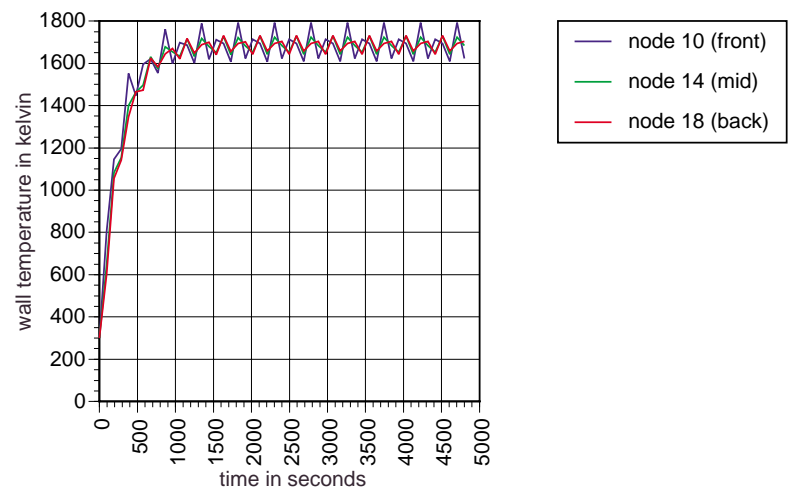

\section{D) Chemical Kinetics for Several Reentry Cases}

Three chemical kinetics cases are shown here for demonstration purposes. Again the 30 second descent of a carbon-carbon aeroshell is the flight. In the first case the gas composition is approximated much as before: .68 mole fraction of molecular nitrogen, .318 mole fraction of $\mathrm{CO}$ and .002 mole fraction of molecular oxygen. The variation with time of the reaction rates of the most active surface reactions are shown in Figure 14. Rate 9, the sublimation of atomic carbon, peaks where the temperature peaks, as expected. Reaction 3, running forward, is molecular oxygen splitting at the surface with one oxygen atom retained by a carbon surface site. Reaction 4, running backwards, is in a sense balancing reaction 3 . When reaction 4 runs backwards it releases a carbon dioxide molecule to the gas phase by virtue of a $\mathrm{CO}$ interaction with an oxygen atom at a carbon surface site. Thus rate 3 is putting $\mathrm{O}$ on the surface and rate 4 is taking $\mathrm{O}$ off. Reaction 1 is also participating with 4 in balancing 3 because reaction 3 running backwards is simple oxygen desorption from an occupied carbon surface site. 
Figure 14. Ablation rates versus time for TOPAZ3D using "baseline gas concentrations" and the surface kinetics option

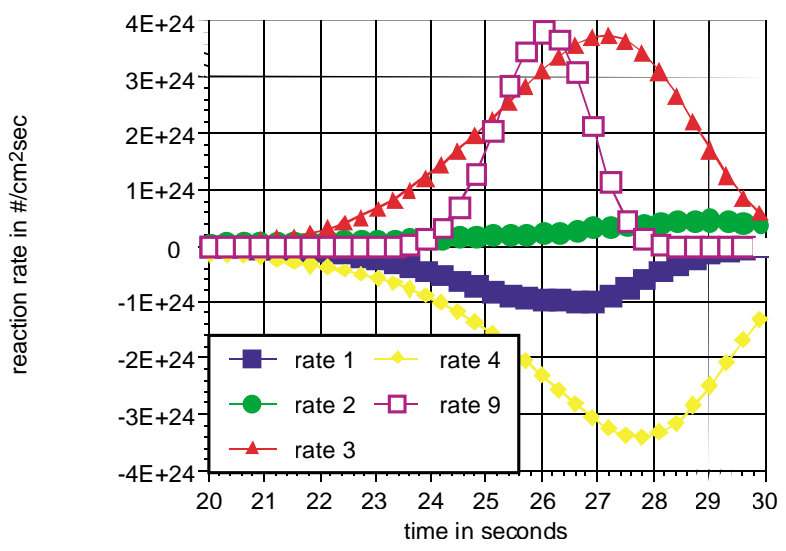

Figure 15 presents a contrasting surface chemistry where the constant gas feed is .68 mole fraction molecular nitrogen, .005 atomic oxygen and .315 carbon monoxide. Since there is no feed of molecular oxygen in this case there is no supply of the reactants needed for reaction 3 . Thus rate 3 does not participate significantly and other mechanisms adjust. Here reactions 1 and 4 are approximately equally balanced. Presumably carbon sublimation is stifled because all or nearly all of the surface sites are covered with oxygen atoms.

Figure 15. Ablation rates versus time for TOPAZ3D using "first perturbed gas concentrations" and the surface kinetics option.

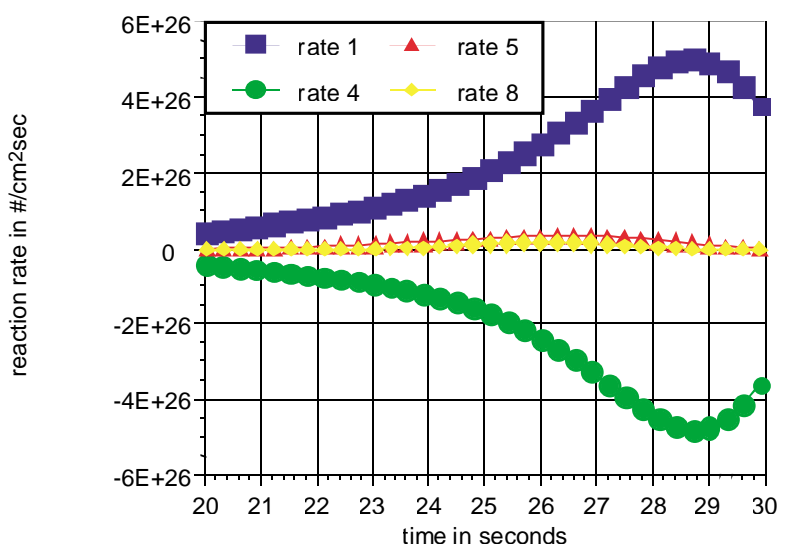

Figure 16 presents a much more speculative case. In an attempt to get the nitrogen bearing reactions involved, numbers 11 and 12 , the gas feed was changed to .66 mole fraction molecular nitrogen, .02 atomic nitrogen, .005 atomic oxygen, .005 molecular oxygen, and .31 carbon monoxide. Nitrogen reactions did not initiate at significant levels, but the interplay of reaction rates did adjust due to the inclusion of more atomic and molecular oxygen in the mix. Rate 5, the generation of simple $\mathrm{CO}$ from oxygen adsorbed on carbon surface sites is far stronger in this case than in either of the other two previous figures.

Figure 16. Ablation rates versus time for TOPAZ3D using "second perturbed gas concentrations" and the surface kinetics option.

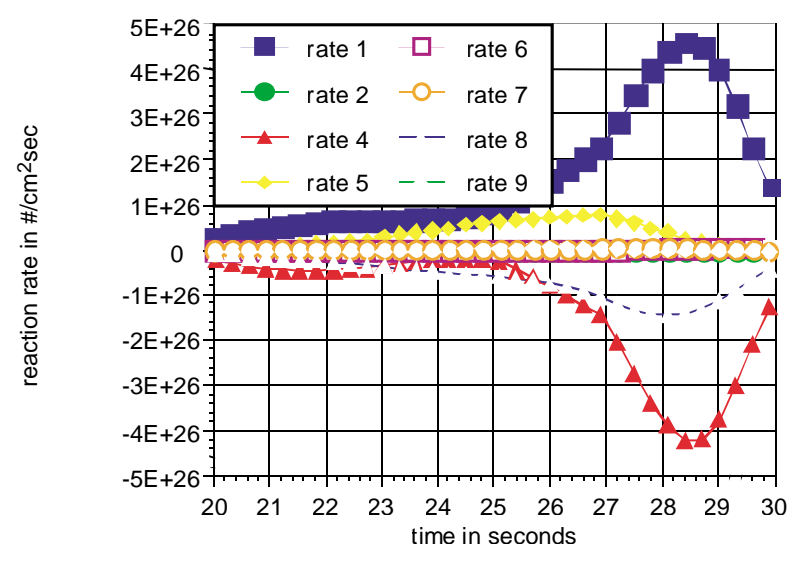

\section{Cases}

E) Chemical Kinetics for Two Hypersoar

The variation in reaction rate for the most active reactions during the first four Hypersoar skips are shown in Figure 17 ( as in the base case above, the gas feed is .68 mole fraction of molecular nitrogen, .318 mole fraction of $\mathrm{CO}$ and .002 mole fraction of molecular oxygen). Reaction 2 is running forward, splitting the molecular oxygen and putting both oxygen atoms on the carbon surface. Reaction 3 is also running forward but more slowly, splitting molecular oxygen and putting a single oxygen atom on the surface. Reaction 4 is running backward, at twice the rate reaction 3 is running forward, forming $\mathrm{CO}_{2}$ from the gaseous atomic oxygen and the $\mathrm{C}-\mathrm{O}$ surface complexes.

The variation in reaction rate for the most active reactions for a gas feed distribution perhaps more representative of the hypersoar flight altitudes is shown in figure 18 (the gas feed is .68 mole fraction of molecular nitrogen, .3088 of $\mathrm{CO}, .0007$ of atomic oxygen, .0005 atomic nitrogen and .01 carbon dioxide). As before, reaction 4 runs backwards, forming carbon dioxide, and nitrogen reactions are inoperative. Reaction 3 runs backward here, forming $\mathrm{O}_{2}$ from the available $\mathrm{O}$ and $\mathrm{C}-\mathrm{O}$ complexes. Reactions 5,6 and 7 run forward releasing $\mathrm{CO}$ and $\mathrm{CO}_{2}$ to the flow field (and accounting for all of the aeroshell mass loss). 
Figure 17. Reaction rates versus time for TOPAZ3D calculation of hypersoar skips using "base case" gas concentrations.

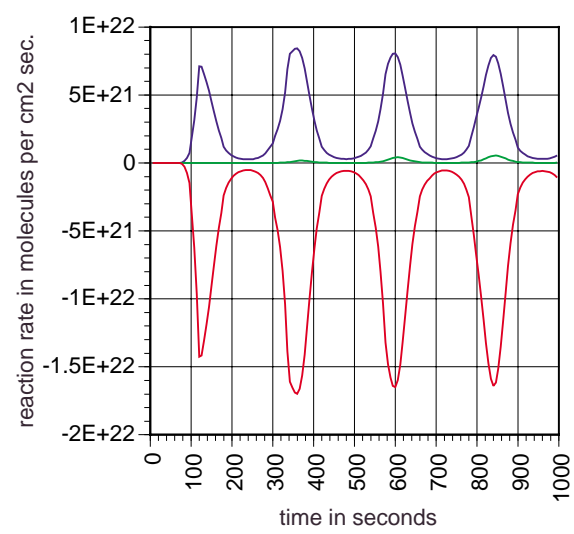

Figure 18. Reaction rates versus time for TOPAZ3D calculation of hypersoar skips using "perturbed case" gas concentrations.
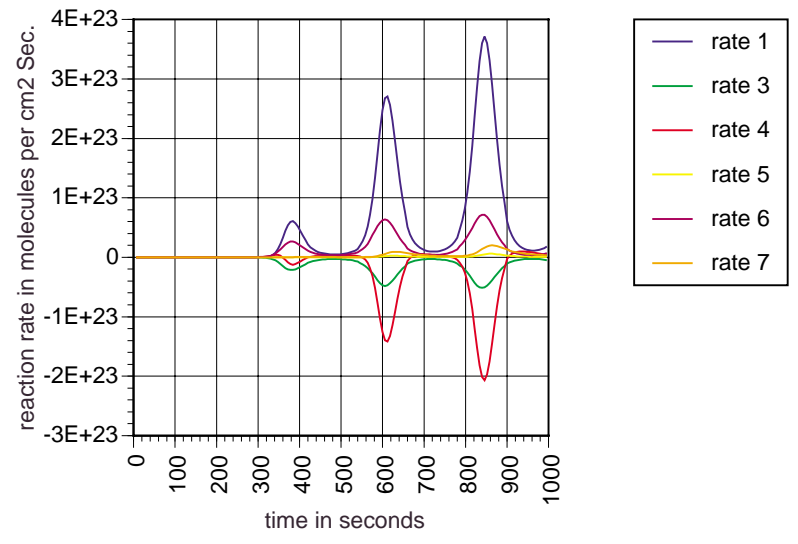

\section{NOMENCLATURE}

a blowing constant

$a_{R} \quad$ constant in rate dependent ablation relation

$\mathrm{B}_{\mathrm{o}}$, nondimensional mass flux

$\mathrm{B} \quad$ surface atom site density

$\mathrm{C}_{\mathrm{m}} \quad$ Stanton number for mass transfer

$\mathrm{C}_{\infty} \quad$ constant in fit to specific heat data

$\mathrm{c}_{\mathrm{p}} \quad$ specific heat

$c_{1} \quad$ constant in fit to equilibrium constant data

$\mathrm{c}_{2} \quad$ constant in fit to equilibrium constant data

D constant in fit to specific heat data

E activation energy

f kinetic rate factor

$\mathrm{G}_{1} \quad$ mean altitude of Hypersoar skip

$\mathrm{G}_{2} \quad$ amplitude of Hypersoar skip

$\mathrm{G}_{3} \quad$ period of Hypersoar skip

h enthalpy

h Planck's constant

$\mathrm{K}$ equilibrium constant

$\mathrm{k}$ reaction rate constant k Boltzmann's constant

L number of surface species

1 surface species index

m mass per molecule

$\dot{m} \quad$ mass flux

$\mathrm{P}^{*} \quad$ nondimensional pressure

$\mathrm{P}_{\mathrm{o}} \quad$ reference pressure

$\mathrm{P}$ pressure

Q number of surface reactions

$\dot{m}$ heat flux

q chemical species index

$\mathrm{R}_{\text {univ }}$ universal gas constant

$\mathrm{r}$ forward reaction rate

S surface kinetic factor

$\mathrm{T}$ temperature

$\mathrm{t}$ time

u velocity

W number of gaseous species

W gaseous species index

$\mathrm{X}$ mole fraction of gaseous species

$\Phi \quad$ modification factor in heat transfer relation

$\mu \quad$ stoichiometric coefficient of gaseous products

$v \quad$ stoichiometric coefficient of gaseous reactants

$\lambda$ stoichiometric coefficient of surface products

$\eta \quad$ stoichiometric coefficient of surface reactants

$\theta \quad$ surface species concentration

$\varepsilon \quad$ emissivity

$\varepsilon \quad$ parameter in surface species reaction constant

$\rho$ density

$\sigma \quad$ stefan-boltzmann constant

\section{$\underline{\text { Subscripts }}$}

$\begin{array}{ll}\text { a } & \text { activation } \\ \text { ab } & \text { ablation } \\ \text { abspec } & \text { ablated species } \\ \text { blow } & \text { blowing } \\ \text { car } & \text { carbon } \\ \text { cw } & \text { cold wall } \\ \text { diff } & \text { diffusion } \\ \text { e } & \text { edge } \\ \text { emittradn } \\ \text { eq } & \text { equilibrium } \\ \text { er } & \text { erosion } \\ \mathrm{f} & \text { forward } \\ \text { flcondn } & \text { fluid conduction } \\ \mathrm{HAL} & \text { heating augmentation level } \\ \mathrm{i} & \text { mass species index } \\ \text { incradn } & \text { incident radiation } \\ \mathrm{k} & \text { element index } \\ \mathrm{m} & \text { reaction index } \\ \mathrm{n} & \text { species index } \\ \text { pyrgas } & \text { pyrolysis gas } \\ \mathrm{q} & \text { reaction index } \\ \mathrm{R} & \text { used in rate dependent relation } \\ \mathrm{r} & \text { reverse } \\ \text { rec } & \text { recovery } \\ \text { ref } & \text { reference }\end{array}$


reflradn reflected radiation

solcondn solid conduction

und underside

univ universal

w wall

\section{Superscripts}

y exponential power in equilibrium constant

$\mathrm{u}$ exponential power in equilibrium constant relations

\section{REFERENCES}

${ }^{1}$ Potts, R.L.,"Application of Integral Methods to Ablation Charring Erosion, A Review," Journal of Spacecraft and Rockets, Vol. 32, No. 2, 1995, pp. 200209.

${ }^{2}$ Leone, S.A., Potts, R.L., Laganelli, A.L., "Enhancements to Integral Solutions to Ablation and Charring," Journal of Spacecraft and Rockets, Vol. 32, No. 2, 1995, pp. 210-216.

${ }^{3}$ Hassan, B., Kuntz, D.W. and Potter, D.L., "Coupled Fluid/Thermal Prediction of Ablating Hypersonic Vehicles,” AIAA paper 98-0168, Jan. 1998.

${ }^{4}$ Keenan, J.A., and Candler, G.V., "Simulation of Graphite Sublimation and Oxidation under Re-Entry Conditions," AIAA paper 94-2083, June 1994.

${ }^{5}$ Zhluktov, S.V., Utyuzhnikov, S.V., and Tirskiy, G.A., "Numerical Investigation of Thermal and Chemical Nonequilibrium Flows past Slender Blunted Cones," Journal of Thermophysics and Heat Transfer, Vol. 10, No. 1, 1996.

${ }^{6}$ Conti, R.J., MacCormack, R.W., Groener, L.S. and Fryer, J.M., "Practical Navier-Stokes Computation of Axisymmetric Reentry Flowfields with Coupled Ablation and Shape Change," AIAA paper No. 920752, January 1992.

${ }^{7}$ Chen, Y.-K. and Henline, W.D., "Hypersonic Nonequillibrium Navier-Stokes Solutions over an Ablating Graphite Nosetip," Journal of Spacecraft and Rockets, Vol. 31, No. 5, 1994.

${ }^{8}$ Keenan, J.A., and Candler, G.V., "Simulation of Ablation in Earth Atmospheric Entry," AIAA paper 932789, July 1993.

${ }^{9}$ Milos, F.S. and Rassky, D.J.,"Review of Numerical Procedures for Computational Surface Thermochemistry," Journal of Thermophysics and Heat Transfer, Vol. 8, No. 1, 1994, pp. 24-34.
${ }^{10}$ Nasuti, F., Barbato, M., and Bruno, C., "Material-Dependent Catalytic Recombination Modeling for Hypersonic Flows," Journal of Thermophysics and Heat Transfer, Vol. 10, No. 1, 1996, pp. 131-136.

${ }^{11}$ Kovalev, V.L., Suslov, O.N., and Tirskiy, G.A., "Phenomenological Theory for Heterogeneous Recombination of Partially Dissociated Air on HighTemperature Surfaces," Molecular Physics and Hypersonic Flows, edited by M. Capitelli, Kluwer Academic Publishers, Netherlands, 1996, pp. 193-201.

${ }^{12}$ Zhluktov, S.V. and Abe, T., "Viscous ShockLayer Simulation of Airflow past Ablating Blunt Body with Carbon Surface," Journal of Thermophysics and Heat Transfer, Vol. 13, No. 1, 1999.

${ }^{13}$ Shapiro, A.B., "TOPAZ3D - A Three Dimensional Finite Element Heat Transfer Code," University of California, Lawrence Livermore National Laboratory, Rept. UCID-20484, 1985.

${ }^{14}$ Anon., “User's Manual Aerotherm Chemical Equilibrium Computer Program (ACE 81)," Acurex Corp., Rept. UM-81-11/ATD, Mountain View, CA, Aug. 1981.

${ }^{15}$ Hove, D.T. and Shih, W.C.L., "Re-Entry Vehicle Stagnation Region Heat-Transfer in Particle Environments," AIAA Journal, Vol. 15, No. 7, 1977, pp. 1002-1005.

${ }^{16}$ Spalding, D.B., Convective Mass Transfer, Edward Arnold Ltd., London, 1963.

${ }^{17}$ Scala, S.M., and Gilbert, L.M., "Sublimation of Graphite at Hypersonic Speeds," AIAA Journal, Vol. 5, No. 9, 1965, pp. 1635-1644.

${ }^{18}$ Metzger, J.W., Engel, M.J. and Diaconis, N.S., "Oxidation and Sublimation of Graphite in Simulated Re-Entry Environments", AIAA Journal, Vol. 5, No. 3, 1967, pp.451-460.

${ }^{19}$ Chase, M.W., et. al., "JANAF Thermochemical Tables, Third Edition", Journal of Physical and Chemical Reference Data, Vol. 14, Sup. 1, 1985.

${ }^{20}$ Blottner, F.G., "Prediction of Electron Density in the Boundary Layer on Entry Vehicles with Ablation," NASA SP-252, Oct. 1970, pp. 219-240.

${ }^{21}$ Zavitsanos, P.D., "The Vaporization of Pyrolytic Graphite," General Electric Co., G.E. R 66 SD 31, May, 1966. 
${ }^{22}$ Park, C., "Review of Chemical-Kinetic Problems of Future NASA Missions, I: Earth Entries," Journal of Thermophysics and Heat Transfer, Vol. 7, No. 3, 1993, pp. 385-398.

${ }^{23}$ Brown, P.N., Byrne, G.D. and Hindmarsh, A.C., "VODE- a variable-Coefficient ODE Solver", University of California, Lawrence Livermore National Laboratory, Rept. UCRL-98412, June 1988.
${ }^{24}$ Baker, R.L., "Graphite Sublimation Chemistry Nonequilibrium Effects," AIAA Journal, Vol. 15, No. 10, 1977, pp. 1391-1397.

${ }^{25}$ Palmer, H.B., and Shelef, M., "Vaporization of Carbon," Chemistry and Physics of Carbon, Vol. 4, Marcel Dekker Inc., New York, 1968, pp. 85-135.

${ }^{26}$ Allen, H.J., and Eggers, A.J., "A Study of the Motion and Aerodynamic Heating of Missiles Entering the Earth's Atmosphere at High Supersonic Speeds," NACA Technical Note 4047, October, 1957. 